\title{
MACRO CONTEXTO CONTEMPORÂNEO E TRANSFORMAÇÕES ECONÔMICAS: OS AJUSTES ESPACIAIS CEARENSES
}

Francisco do O’ de Lima Júnior ${ }^{1}$

Resumo: Este trabalho analisa os ajustes espaciais cearenses face ao macro contexto contemporâneo de transformações econômicas. Partiu-se da hipótese de que os movimentos da reestruturação econômica exigiram ajustes territoriais profundos, redimensionando os papéis exercidos pelos centros urbanos a partir da lógica produtiva assumida por cada um deles. Seguiu-se método descritivo históricoestrutural, utilizando dados secundários de órgãos oficiais (IBGE, MIDIC, e IPECE). Observou-se que os mecanismos de ajustes conformam o atual sistema urbano estadual, funcionalizados pela emersão de três arranjos estruturais urbanos nítidos com i) o avanço na metropolização, ii) o gradativo crescimento de centros intermediários constituídos por cidades médias polos de atração industrial incentivada e iii) os pequenos centros ligados às reservas dos espaços rurais em modernização via fruticultura irrigada.

Palavras-chave: Ceará, mudanças econômicas, reorganização urbano-regional.

\section{MACRO CONTEXT CONTEMPORARY AND ECONOMIC TRANSFORMATIONS: CEARENSES SPATIAL ADJUSTMENTS}

Abstract: This paper analyzes the spatial adjustments of Ceará in the contemporary context of economic transformations. It was hypothesized that the movements of economic restructuring required deep territorial adjustments, re-dimensioning the roles of urban centers based on the productive logic assumed by each one of them. Follow the historical-structural descriptive method, using secondary data from official bodies (IBGE, MIDIC, and IPECE). It was observed that it is a mechanism of adjustment according to the present state urban system, functionalized by emersion of three clear urban structural arrangements with i) the advance in the metropolization, ii) the gradual growth of intermediate centers constituted by mediumsized cities of industrial Curiosidade incentivada and iii) small centers linked to the reserves of rural spaces in modernization via irrigated fruit farming.

Keywords: Ceará, economic change, urban-regional reorganization.

\section{MACRO CONTEXTO CONTEMPORÁNEO Y TRANSFORMACIONES ECONÓMICAS: LOS AJUSTES ESPACIALES CEARENSES}

Resumen: Este trabajo analiza los ajustes espaciales cearenses frente al macro contexto contemporáneo de transformaciones económicas. Se partió de la hipótesis de que los movimientos de la reestructuración económica exigieron ajustes territoriales profundos, redimensionando los papeles ejercidos por los centros urbanos a partir de la lógica productiva asumida por cada uno de ellos. Seguir método descriptivo histórico-estructural, utilizar datos secundarios de órganos oficiales (IBGE, MIDIC, e IPECE). Se observó que es un mecanismo de ajuste

\footnotetext{
1 Universidade Regional do Cariri (URCA), Departamento de Economia, Crato/CE, Brasil,
} lima.junior@urca.br, https://orcid.org/0000-0002-1825-0097 
conforme al actual sistema urbano estatal, funcionalizado por emersión de tres arreglos estructurales urbanos nítidos con i) el avance en la metropolización, ii) el gradiente crecimiento de centros intermediarios constituidos por ciudades medias polas de Curiosidad industrial incentivada y iii) los pequeños centros vinculados a las reservas de los espacios rurales en modernización a través de la fruticultura irrigada.

Palabras clave: Ceará, cambios económicos, reorganización urbano-regional.

\section{Introdução}

A recente dinâmica de transformações mundiais impondo novos condicionantes na arena econômica, mobilizadas pela modernização tecnológica com consequências nas esferas produtiva, informacional e de transportes, trouxe imposições reestruturantes. Promoveu-se uma rápida reorientação nas formas de acumulação em que dois aspectos se sobressaem: uma nova divisão mundial do trabalho motivada pela incessante busca de redução de custos via flexibilização e desregulamentação cada vez mais invasivas e, a emergência do padrão de acumulação financeira como predominante.

A economia brasileira acompanha tais transformações. Sua inserção ocorreu nos limites dados por suas características estruturais de país periférico, associadas à heterogeneidade do seu desenvolvimento. A sua adesão ao padrão de regulação neoliberal, juntamente com desgastes nas fontes de financiamento causadas pelo endividamento público, reduziu as margens de ação política para promoção do desenvolvimento, mais especificamente nos seus aspectos territoriais.

Legitima-se assim a inserção pautada nos elementos de competitividade. Os ajustes espaciais reproduzem esta lógica, com as atividades econômicas imprimindo movimentos que traduzem tal busca por redução de custos. Os territórios com fatores vantajosos como mão de obra, infraestrutura, disponibilidade de matérias primas passam a ser atrativos e benefícios - principalmente as de caráter fiscal, dentre tantas outras -, oferecidos por governos estaduais e municipais somam-se como determinantes.

Com uma população de 8.452 .381 habitantes dos quais $75 \%$ vivem em áreas urbanas (IBGE, 2010), o Estado do Ceará se inseriu nesta dinâmica como parte do grupo de economias mais preponderantes na Região Nordeste do Brasil, juntamente com os Estados da Bahia e Pernambuco. Deste grupo, foi a que mais cresceu entre os anos de 2000-10 sendo suas respectivas Taxas de Crescimento Anual do PIB: 3,1\% (Bahia), 4,3\% (Ceará) e 2,0\% (Pernambuco). Com o arrefecimento das 
políticas nacionais e regionais de desenvolvimento, a saída mais crível foi a prática da guerra fiscal. No caso cearense entretanto, assistiu-se inicialmente a um conjunto de mudanças que partiram do campo político-econômico com rupturas na forma de gestão pública já na segunda metade dos anos 1980. As etapas seguidas foram de ajustes administrativos-fiscais reorganizando a máquina pública para, segundo preconizado pelos adeptos de tal modelo, recuperar a capacidade de promoção do desenvolvimento. A justificativa estava na busca por mudanças econômicas e sociais modernizadoras, inserindo o estado nos movimentos da economia global.

Os impactos territoriais provinham das formas de estímulo às atividades produtivas e atração de investimentos sistematizados de maneira diferenciadas no espaço, segundo suas particularidades de localização, físicas, de formação e de outros aspectos de atração como a abundante oferta de mão de obra. $O$ tripé indústria-turismo-agronegócio foi priorizado nas ações implantadas e as sete mesorregiões do Ceará absorveram os efeitos desta forma de inserção nas transformações econômicas, reorganizando alguns elementos espaciais do seu desenvolvimento.

É importante destacar o papel exercido por aspectos do contexto macro, que marcam a conjuntura delineada pós-2003 como: os efeitos dos programas de transferências de renda que tiveram sua expansão; a retomada do crédito ao consumo; a recomposição do poder de compra das classes mais populares; a recuperação - ainda que tímida - do investimento público associada às ações do Programa de Aceleração do Crescimento - PAC e; o desempenho do comércio internacional e as formas de inserção brasileira, motivada primordialmente pelo "efeito China" cujo foco direciona-se para o conjunto de produtos de origem agrícola e mineral, secundada de bens não duráveis. Estes elementos arrefeceram com a crise econômica e política mais recentes.

Os resultados apontam para efetivas alterações na dinâmica econômica promovendo mudanças espaciais no estado mantendo entretanto aspectos de sua configuração passada. A expansão do PIB setorial cearense entre 1999 e 2010 reafirma o dinamismo das atividades urbanas e não mais rurais: agropecuária, indústria e serviços cresceram $6,5 \%, 11,3 \%$ e $12,1 \%$ a.a. respectivamente (IBGE, 2010).

Desta forma, o objetivo deste trabalho é analisar os reflexos das mudanças econômicas recentes sobre o reordenamento espacial do Estado do Ceará durante a primeira década do século XXI. A hipótese é que esta dinâmica promoveu ajustes 
espaciais com nítida reorganização terrritorial, onde se sobressaem arranjos estruturais urbanos que Ihes são funcionais como os processos i) de metropolização, ii) crescimento de cidades médias e iii) inserção das pequenas cidades como reservas de fatores para transformação, articulando os mundos rural e urbano.

Metodologicamente, os efeitos no espaço estadual são captados em diversas óticas abrangendo amplo leque de categorias que dão contribuições na elaboração de uma resposta à hipótese proposta, permitindo entender como este espaço responde ao macro contexto econômico a partir das articulações feitas pelo seu sistema urbano. Para tanto, o trabalho está dividido em duas partes além desta introdução e das considerações finais. Na primeira são tratadas algumas notas de revisão bibliográfica confrontando-as aos movimentos da dinâmica econômica recente e suas implicações territoriais no Ceará.

A segunda seção discute de forma mais direta os movimentos de ajuste e a emergência dos concernentes arranjos estruturais urbanos que os consolidam em sincronia com a proposição de "spatial fix" preconizada por Harvey (2005, p. 121). Manifestando nitidamente as reorganizações urbano-espaciais no Estado do Ceará, estes arranjos são analisados especificamente em cada uma das subseções, e na sequência a seção com as Conclusões.

\section{Notas bibliográficas e os episódios da reestruturação econômica, movimentos de ajuste e reordenamentos espaciais.}

A configuração espacial do Ceará, fundada na análise dos fluxos de influência dos seus centros urbanos, resulta na disposição de uma organização que traduz seguramente as formas de inserção no padrão de divisão espacial do trabalho predominante, dado pelos movimentos da dinâmica produtiva.

As delimitações deste padrão ditaram as condições em que se assentaram os vetores da economia a partir dos anos 1980 com a arrancada da gestão modernizadora denominada de "Governo das Mudanças". A apropriação via reordenamentos do território nesta rodada da acumulação capitalista, operacionalizada no tripé condutor das mudanças (agronegócio-indústria-turismo), sedimentou o aspecto contraditório que caracteriza este espaço onde mutaçãopermanências são embates com relação recíproca.

As mutações se verificam sob diversas óticas. A começar pela processual desconcentração econômica com redução da participação da capital do estado em 
alguns indicadores. Conforme Tabela 2, a capital Fortaleza concentrava 61,5\% do PIB das atividades industriais em meados dos anos 1980, reduzindo esta participação para $42 \%$ em 2010. No setor terciário sensíveis mudanças também se verificaram com uma queda na participação da capital de $62,7 \%$ para $51 \%$ (Tabela 3). Neste grande setor, três segmentos foram líderes de queda do percentual de participação fortalezense entre os anos de 1991 e 2010: o Comércio (de 58,2\% para 54,1\%), Prestação de Serviços (incluindo Alojamento, Alimentação e Serviços Domésticos) (70,6\% para 54,3\%) e Serviços da Administração Pública (de 57,5\% 45,3\%) (Tabela 4).

Tabela 1 - Ceará: Dez maiores PIB’s municipais na Agropecuária 1985-2010.

\begin{tabular}{|c|c|c|c|c|c|c|c|c|c|}
\hline & \multicolumn{3}{|c|}{1985} & \multicolumn{3}{|c|}{2000} & \multicolumn{3}{|c|}{2010} \\
\hline & Município & $\begin{array}{l}\text { PIB } \\
\text { (mil } \\
\text { R\$) }\end{array}$ & $\begin{array}{c}\text { \% do } \\
\text { Estado }\end{array}$ & Município & $\begin{array}{l}\text { PIB } \\
\text { (mil } \\
\text { R\$) }\end{array}$ & $\begin{array}{c}\text { \% do } \\
\text { Estado }\end{array}$ & Município & $\begin{array}{l}\text { PIB } \\
\text { (mil } \\
\mathbf{R} \$ \text { ) }\end{array}$ & $\begin{array}{c}\text { \% do } \\
\text { Estado }\end{array}$ \\
\hline 19. & Iguatu & 64,5 & 2,8 & Tianguá & 37,6 & 2,5 & Tianguá & 36,6 & 2,9 \\
\hline $2^{\circ}$ & Quixadá & 63,0 & 2,7 & Ibiapina & 28,3 & 1,8 & Icapuí & 35,7 & 2,8 \\
\hline 3 . & Itapipoca & 60,5 & 2,6 & Itapipoca & 25,0 & 1,6 & Aracati & 29,8 & 2,4 \\
\hline $4 \%$. & Quixeramobim & 50,7 & 2,2 & Quixadá & 23,9 & 1,6 & $\begin{array}{l}\text { São } \\
\text { Benedito }\end{array}$ & 24,5 & 1,9 \\
\hline 5o. & Morada Nova & 50,2 & 2,2 & Ubajara & 23,8 & 1,6 & Ibiapina & 24,5 & 1,9 \\
\hline $6 \circ$. & Acaraú & 48,6 & 2,1 & Aracati & 23,2 & 1,5 & $\begin{array}{l}\text { Limoeiro do } \\
\text { Norte }\end{array}$ & 23,5 & 1,9 \\
\hline $7^{\circ}$. & Tauá & 48,5 & 2,1 & Quixeramobim & 23,1 & 1,5 & Russas & 23,4 & 1,8 \\
\hline $8 \%$ & Acopiara & 44,6 & 1,9 & $\begin{array}{l}\text { Limoeiro do } \\
\text { Norte }\end{array}$ & 22,2 & 1,4 & $\begin{array}{l}\text { Guaraciaba } \\
\text { do Norte }\end{array}$ & 22,0 & 1,7 \\
\hline 9‥ & Aracati & 42,9 & 1,9 & Iguatu & 21,9 & 1,4 & $\begin{array}{l}\text { Morada } \\
\text { Nova }\end{array}$ & 20,1 & 1,6 \\
\hline 10 . & Maranguape & 40,5 & 1,8 & Tauá & 19,9 & 1,3 & Ubajara & 19,4 & 1,5 \\
\hline TOTAL & & 519,9 & 22,3 & & 248,9 & 16,2 & & 259,5 & 20,5 \\
\hline
\end{tabular}

Fonte: PIB's Municipais (IBGE, 2013)

Tabela 2 - Ceará: Dez maiores PIB’S municipais na Indústria 1985-2010.

\begin{tabular}{|c|c|c|c|c|c|c|c|c|c|}
\hline & \multicolumn{3}{|c|}{1985} & \multicolumn{3}{|c|}{2000} & \multicolumn{3}{|c|}{2010} \\
\hline & Município & $\begin{array}{l}\text { PIB } \\
\text { (mil } \\
\text { R\$) }\end{array}$ & $\begin{array}{l}\text { \% do } \\
\text { Estado }\end{array}$ & Município & $\begin{array}{l}\text { PIB } \\
\text { (mil } \\
\text { R\$) }\end{array}$ & $\begin{array}{l}\text { \% do } \\
\text { Estado }\end{array}$ & Município & $\begin{array}{c}\text { PIB (mil } \\
\text { R\$) }\end{array}$ & $\begin{array}{l}\text { \% do } \\
\text { Estado }\end{array}$ \\
\hline $1 \%$ & Fortaleza & $2.490,5$ & 61,5 & Fortaleza & $1.955,0$ & 40,6 & Fortaleza & 3033,8 & 42,0 \\
\hline 2음 & Maracanaú & 305,6 & 7,5 & Maracanaú & 672,2 & 13,9 & Maracanaú & 811,7 & 11,2 \\
\hline 3․ & Sobral & 140,9 & 3,5 & Sobral & 282,5 & 5,9 & Sobral & 337,3 & 4,7 \\
\hline $4^{\circ}$. & Caucaia & 99,4 & 2,5 & Caucaia & 152,3 & 3,2 & Caucaia & 336,1 & 4,7 \\
\hline 5‥ & $\begin{array}{l}\text { Juazeiro do } \\
\text { Norte }\end{array}$ & 76,0 & 1,9 & Eusébio & 150,5 & 3,1 & Eusébio & 260,3 & 3,6 \\
\hline $6 \%$ & Aracati & 73,8 & 1,8 & Pacajus & 126,5 & 2,6 & Horizonte & 192,4 & 2,7 \\
\hline $7^{\circ}$. & Aquiraz & 66,7 & 1,6 & Horizonte & 122,0 & 2,5 & $\begin{array}{l}\text { Juazeiro do } \\
\text { Norte }\end{array}$ & 150,0 & 2,1 \\
\hline $8 \%$ & Maranguape & 57,9 & 1,4 & Juazeiro do & 90,4 & 1,9 & Aquiraz & 115,2 & 1,6 \\
\hline
\end{tabular}




\begin{tabular}{|c|c|c|c|c|c|c|c|c|c|}
\hline & & & & Norte & & & & & \\
\hline $9 \stackrel{\text {. }}{ }$ & Cascavel & 50,5 & 1,2 & Aquiraz & 65,9 & 1,4 & Maranguape & 114,1 & 1,6 \\
\hline $10 \%$ & Pacajus & 46,3 & 1,1 & Cascavel & 62,0 & 1,3 & Pacatuba & 96,6 & 1,3 \\
\hline TOTAL & & $3.407,6$ & 84,1 & & $3.679,3$ & 76,3 & & $5.447,4$ & 75,4 \\
\hline
\end{tabular}

Fonte: PIB's Municipais (IBGE, 2013)

Tabela 3 - Ceará: Dez maiores PIB’S municipais nos Serviços 1985-2010.

\begin{tabular}{|c|c|c|c|c|c|c|c|c|c|}
\hline & \multicolumn{3}{|c|}{1985} & \multicolumn{3}{|c|}{2000} & \multicolumn{3}{|c|}{2010} \\
\hline & Município & $\begin{array}{l}\text { PIB } \\
\text { (mil } \\
\text { R\$) }\end{array}$ & $\begin{array}{l}\text { \% do } \\
\text { Estado }\end{array}$ & Município & $\begin{array}{l}\text { PIB } \\
\text { (mil } \\
\text { R\$) }\end{array}$ & $\begin{array}{l}\% \text { do } \\
\text { Estado }\end{array}$ & Município & $\begin{array}{l}\text { PIB (mil } \\
\text { R\$) }\end{array}$ & $\begin{array}{l}\text { \% do } \\
\text { Estado }\end{array}$ \\
\hline $1 \%$ & Fortaleza & $5.336,6$ & 62,7 & Fortaleza & $7.493,8$ & 55,1 & Fortaleza & $11.211,5$ & 51,0 \\
\hline $2^{\circ}$ & Maracanaú & 201,6 & 2,4 & Maracanaú & 453,7 & 3,3 & Maracanaú & 742,0 & 3,4 \\
\hline 3 & $\begin{array}{l}\text { Juazeiro do } \\
\text { Norte }\end{array}$ & 137,3 & 1,6 & Caucaia & 372,0 & 2,7 & Caucaia & 678,9 & 3,1 \\
\hline 4‥ & Sobral & 135,6 & 1,6 & Sobral & 367,0 & 2,6 & $\begin{array}{l}\text { Juazeiro do } \\
\text { Norte }\end{array}$ & 634,8 & 2,9 \\
\hline 5․ & Crato & 122,8 & 1,4 & $\begin{array}{l}\text { Juazeiro do } \\
\text { Norte }\end{array}$ & 328,1 & 2,4 & Sobral & 557,9 & 2,5 \\
\hline $6 \%$ & Caucaia & 118,5 & 1,3 & Crato & 186,5 & 1,4 & Crato & 275,4 & 1,3 \\
\hline 7‥ & Iguatu & 82,1 & 1,0 & Iguatu & 146,0 & 1,1 & Quixeré & 263,6 & 1,2 \\
\hline 8 . & Quixadá & 78,9 & 0,9 & Maranguape & 104,3 & 0,8 & Iguatu & 238,2 & 1,1 \\
\hline $9 \stackrel{\text {. }}{9}$ & Maranguape & 78,2 & 0,9 & Eusébio & 103,9 & 0,8 & Eusébio & 187,1 & 0,9 \\
\hline 10 . & Aracati & 71,6 & 0,8 & Itapipoca & 99,1 & 0,7 & Itapipoca & 178,6 & 0,8 \\
\hline TOTAL & & $6.636,2$ & 74,7 & & $9.654,3$ & 71,0 & & $14.967,8 \%$ & 68,1 \\
\hline
\end{tabular}

Fonte: PIB's Municipais (IBGE, 2013).

No campo da Agropecuária, as mutações se expressaram na substituição do peso da produção de culturas tradicionais, geralmente localizadas nas mesorregiões mais atrasadas (Sertões e Centro Sul Cearenses), por aquelas voltadas ao cultivo em atividades de inserção externa (situadas nos municípios de Tianguá, São Benedito, Icapuí, Aracati, Russas e Limoeiro do Norte), elevando a participação destes municípios no PIB Agrícola. Os três últimos despontaram como centros urbanos na articulação da Mesorregião Jaguaribe, maior produtora de fruticultura irrigada do estado. Além das evidencias territorializadas, as setorializadas se adicionam ao conjunto de transformações: o deslocamento da antiga agricultura de sequeiro voltada pra culturas tradicionais (feijão, milho e algodão), por ramos mais modernos, de irrigação e prioritariamente destinados ao comércio externo (melão, melancia, castanha de caju). Os programas de irrigação e a própria política hídrica estadual passam a atender esta lógica.

Já na oferta de serviços, o movimento de mutação foi intenso. A queda de participação de Fortaleza nos ramos comerciais são absorvidas pelas mesorregiões 
interioranas conforme abaliza a Tabela 4. $\mathrm{O}$ crescimento do Comércio no interior se deu mais no nível varejista. Este crescimento reflete as transformações econômicas de inclusão de massas ao consumo e também associa-se à modernização destes padrões vivenciada em muitas cidades médias que receberam grandes indústrias subvencionadas, empresas comerciais e de serviços como shoppings centers e redes de supermercados.

Nas permanências, associadas à noção de rugosidades impressas na formação e consolidação do complexo urbano cearense, algumas características se conservam com o avanço das mutações citadas (SANTOS, 1985, p. 132). O processo de desconcentração apontado pode ser tido como um deles e advém em dois sentidos, dando feições de uma "desconcentração concentrada".

Isto ocorre na consolidação do predomínio não somente de Fortaleza mas da sua Região Metropolitana revisitando o conceito de primazia, extrapolando-o para a noção de espaço primaz incorporando à dinâmica dos centros urbanos imediatamente adjacentes. A "desconcentração concentrada" se manifesta ainda na definição de centros urbanos estratégicos como polos de desenvolvimento reproduzindo a concentração em escalas menores. Maioria destes centros é formada pelos tradicionais polos de atividades, que despontavam como tal em outros momentos da história como Sobral, o aglomerado Crato-Juazeiro do NorteBarbalha, Iguatu, Crateús, Quixadá, Itapipoca.

Observando os serviços, embora também com ampliação da participação de outros centros, em alguns ramos mais específicos como o de serviços e consumos mais sofisticados, o processo é inverso. Nos Serviços Auxiliares das Atividades Econômicas, que compreendem algumas atividades mais elaboradas e com formação profissional técnica mais específica, a participação da Mesorregião Metropolitana se eleva de 57,6\% para 75,8\% (Tabela 4).

Outra constatação está na montagem dos fixos de infraestrutura pesada que reafirma a concentração espacial metropolitana nas melhorias de acesso entre os centros de produção e a RMF, principal canal de ligação/escoamento. A implantação do Complexo Industrial e Portuário do Pecém (CIPP), para além da intensão de dar continuidade às etapas de industrialização estadual na instalação de uma indústria de bens intermediários, traduz as necessidades competitivas com boa estrutura de transporte.

A articulação feita com tal instrumento explicita-se na ótica de uma economia moderna e competitiva, avançando no projeto de inserção externa. A participação 
das atividades que protagonizaram a reestruturação produtiva e espacial, tanto nos ramos agrícolas como industriais, prevalece no quantum das exportações. 
Tabela 4 - Ceará e Mesorregiões Cearenses: Taxa de participação nas ocupações das atividades terciárias (\%) $1991-2010$.

\begin{tabular}{|c|c|c|c|c|c|c|c|c|c|c|c|c|c|c|c|c|c|c|c|c|c|}
\hline & \multicolumn{3}{|c|}{ NOROESTE } & \multicolumn{3}{|c|}{ NORTE } & \multicolumn{3}{|c|}{ METROPOLITANA } & \multicolumn{3}{|c|}{ SERTÕES } & \multicolumn{3}{|c|}{ JAGUARIBE } & \multicolumn{3}{|c|}{ CENTRO-SUL } & \multicolumn{3}{|c|}{ SUL } \\
\hline & 1991 & 2000 & 2010 & 1991 & 2000 & 2010 & 1991 & 2000 & 2010 & 1991 & 2000 & 2010 & 1991 & 2000 & 2010 & $\begin{array}{l}199 \\
1 \\
\end{array}$ & 2000 & 2010 & $\begin{array}{l}199 \\
1\end{array}$ & 2000 & 2010 \\
\hline Comercio & 10,6 & 11,6 & 11,2 & 7,1 & 7,9 & 8,0 & 58,2 & 53,6 & 54,1 & 6,6 & 7,0 & 7,1 & 4,3 & 5,3 & 5,0 & 3,4 & 3,7 & 3,8 & 9,8 & 10,9 & 10,7 \\
\hline $\begin{array}{l}\text { Transp. e } \\
\text { Comunic. }\end{array}$ & 10,5 & 11,4 & 8,7 & 7,6 & 8,5 & 7,1 & 57,5 & 52,2 & 62,0 & 5,7 & 7,5 & 5,7 & 6,0 & 5,8 & 4,3 & 3,0 & 3,9 & 2,9 & 9,7 & 10,7 & 9,4 \\
\hline $\begin{array}{l}\text { Serv. Aux. } \\
\text { das ativ. } \\
\text { Econômicas }{ }^{1}\end{array}$ & 10,4 & 6,4 & 5,8 & 7,6 & 6,1 & 3,7 & 57,6 & 67,6 & 75,8 & 5,7 & 5,5 & 3,9 & 6,0 & 4,3 & 2,7 & 3,0 & 2,3 & 2,1 & 9,7 & 7,7 & 6,1 \\
\hline $\begin{array}{l}\text { Prestação de } \\
\text { serviços }^{2}\end{array}$ & 7,5 & 12,4 & 11,4 & 4,0 & 9,7 & 9,6 & 70,6 & 50,7 & 54,3 & 3,4 & 7,8 & 7,3 & 4,4 & 5,5 & 4,8 & 2,6 & 4,2 & 3,4 & 7,5 & 9,8 & 9,2 \\
\hline Social $^{3}$ & 12,6 & 11,1 & 10,7 & 9,8 & 8,9 & 8,8 & 45,2 & 54,3 & 57,2 & 10,3 & 7,3 & 6,8 & 6,2 & 5,2 & 4,5 & 5,3 & 3,8 & 3,2 & 10,7 & 9,3 & 8,8 \\
\hline $\begin{array}{l}\text { Atv. Financ. e } \\
\text { de seguro }{ }^{4}\end{array}$ & & 5,2 & 7,7 & & 1,7 & 6,3 & & 79,8 & 67,9 & & 2,6 & 5,1 & & 1,2 & 2,9 & & 2,6 & 2,4 & & 6,9 & 7,6 \\
\hline $\begin{array}{l}\text { Administração } \\
\text { pública }\end{array}$ & 8,6 & 13,7 & 13,7 & 7,8 & 10,9 & 11,3 & 57,5 & 44,6 & 45,3 & 8,1 & 10,1 & 9,4 & 6,5 & 6,5 & 5,8 & 3,8 & 5,4 & 4,1 & 7,6 & 8,9 & 10,4 \\
\hline $\begin{array}{l}\text { Outras } \\
\text { atividades }\end{array}$ & 9,4 & 10,4 & 8,8 & 5,0 & 7,5 & 7,4 & 67,6 & 53,6 & 62,3 & 3,5 & 7,0 & 5,6 & 4,1 & 6,9 & 4,5 & 2,3 & 3,6 & 2,7 & 8,1 & 10,9 & 8,7 \\
\hline TOTAL & 10,7 & 11,4 & 10,9 & 7,7 & 8,7 & 8,6 & 55,7 & 53,1 & 55,0 & 7,3 & 7,5 & 7,0 & 5,3 & 5,5 & 4,8 & 3,8 & 3,9 & 3,5 & 9,6 & 9,9 & 9,6 \\
\hline
\end{tabular}

Fonte: Censos Demográficos (1991; 2000; 2010)

Notas: ${ }^{1}$ Serviços Técnico-profissionais

2 Compreende Alojamento, Alimentação e Serviços Domésticos

${ }^{3}$ Educação, Saúde e Serviços

${ }^{4}$ Não disponível para nível Mesorregional em 1991. 
Não obstante não ser objetivo direto estudar o desempenho do Comércio Exterior estadual neste artigo, ressalvas acerca são necessárias tendo em vista a estratégia de inserção competitiva externa tão apregoada nos discursos de política econômica.

Uma das evidências está na observação das exportações por produtos, destaque os provenientes da fruticultura irrigada, como a castanha-de-caju, que em 2010 detinha 14,3\% das exportações estaduais e o melão, com 5,8\%. Quando se considera a lista dos 20 produtos mais exportados pelo Ceará a partir de 2000, os demais produtos são itens que formam o setor de Calçados e seus ramos componentes de Plástico e/ou Couro (com 36,1\%, 36,5\% e 41,4\% dos produtos exportados em 2000, 2005 e 2010 conforme as Tabelas I, II e II em Anexos), acompanhados pelo setor Têxtil ( $2 \%, 2,1 \%$ e $2,8 \%$ nos mesmos anos). Tem relevância ainda na lista produtos como pescados e ceras.

As reestruturações produtiva e espacial articuladas em resposta ao macro contexto contemporâneo se acomodam, privilegiando concentração e inserção externa na reprodução territorial. Os estudos do IBGE através das Regiões de Influências de Cidades apresentados pelo REGIC 2008 para o Ceará refletem a amplitude da relação das mutações-permanências, que na sua ossatura reafirmam seus núcleos como plataforma passiva de divisão espacial do trabalho em ajustes constantes, fornecendo arranjos estruturais sob os determinantes renovadores da lógica de acumulação (CORRÊA, 2011, p. 25). A hipótese de ajustes como decorrência das implicações de inserção da economia brasileira à dinâmica das mudanças do sistema capitalista fica explícita. Nos seus arranjos estruturais é possível ordená-los em três perfis de espacialização: 0 movimento de metropolização, a evolução das cidades médias e a inserção dos demais níveis de cidades.

\section{Reorganização urbano-regional: os arranjos estruturais urbanos da rede cearense.}

\section{A Região Metropolitana de Fortaleza.}

Aspectos compreendidos na convergência para o processo de metropolização de Fortaleza estão presentes ao longo da formação econômica cearense. As estruturas de ocupação espacial implantadas e transformadas também no bojo desta formação, já colocam em si os fundamentos do grande peso que a cidade e sua 
região metropolitana firmaram como topo da rede urbana estadual. O elemento catalisador esteve no papel exercido pelo capital mercantil com base na agro exportação algodoeira.

No momento inicial, o surgimento das metrópoles brasileiras esteve associado à rápida industrialização, implantada a partir do eixo dinâmico Sul-Sudeste e sob o comando paulista em pleno vapor do processo de substituição de importações e da diversificação/integração produtiva nacional. A localização industrial, preconizando a concentração, conduziu a urbanização também concentrada das grandes cidades, sendo a maioria capitais estaduais².

Quando se observa o arranjo presente na metropolização de Fortaleza, são evidentes as relações cumpridas no papel da indústria induzida pela implantação do III Polo Industrial do Nordeste no final dos anos 1970.

As mudanças executadas da segunda metade dos anos $1950 \mathrm{em}$ diante, no âmbito dos governos estaduais, acompanhando as ações de planejamento e promoção do desenvolvimento em vigor no Brasil, fizeram parte de um estágio de ações que sedimentaram os elementos propícios à expansão da capital cearense. Dentre eles estão a criação do BNB, a instauração da Universidade Federal do Ceará, a ligação à rede de eletrificação vinda de Paulo Afonso. Não se pode prescindir ainda a relação feita entre as fases de expansão populacional de Fortaleza com os momentos de manifestação da intempérie climática da seca que situa os períodos pontuais de crescimento da população da capital antes dos anos 1950.

A partir de então os dois vetores se somam ocasionando explosão das taxas de aumento demográfico (Tabela 5). Os períodos de 1950-1960 e 1960-1970 foram as fases de maior crescimento, com respectivas taxas de $6,7 \%$ a.a. e 5,1\%a.a., quando se combinaram uma forte seca (de 1958) com as transformações institucionais fazendo da cidade um centro de serviços diversificados pela criação/instalação de vários órgãos federais e estaduais. (BOZARCCHIELLO, 2007, p. 102).

Tabela 5 - Brasil, Nordeste, Ceará e Fortaleza: Taxa de Crescimento da População 1872-2010.

2 Lencione (2006, p. 49) lembra que instauração e consolidação do fato metropolitano não necessariamente está associado ao avanço das atividades industriais e sim mais diretamente aos serviços ampliados e diversificados. 


\begin{tabular}{l|cccc}
\hline Anos & Brasil & Nordeste & Ceará & Fortaleza \\
\hline $1872-1890$ & 2,1 & 1,4 & 0,6 & $-0,2$ \\
$1890-1900$ & 2,0 & 1,2 & 0,5 & 1,7 \\
$1900-1920$ & 2,9 & 2,6 & 2,2 & 2,5 \\
$1920-1940$ & 1,5 & 1,3 & 2,3 & 4,3 \\
$1940-1950$ & 2,3 & 2,2 & 2,6 & 4,1 \\
$1950-1960$ & 3,2 & 2,2 & 2,2 & 6,7 \\
$1960-1970$ & 2,9 & 2,5 & 3,0 & 5,1 \\
$1970-1980$ & 2,5 & 2,1 & 1,8 & 4,5 \\
$1980-1991$ & 1,8 & 1,7 & 1,5 & 2,8 \\
$1991-2000$ & 1,6 & 1,3 & 1,7 & 2,1 \\
$2000-2010$ & 0,9 & 0,8 & 1,0 & 0,8 \\
\hline
\end{tabular}

Fonte: IBGE (Censos, vários anos).

A partir da segunda metade da década de 1970, o padrão metropolitano de crescimento ganha força tanto pelo crescimento populacional quanto pela ampliação na participação das atividades econômicas. Adiciona-se ainda a gradativa incorporação de municípios vizinhos, processo no qual a instalação do Distrito Industrial foi ponto importante ${ }^{3}$. Se compunham então os sinais do que viria a ser a metrópole e lançavam-se as bases para, num estágio posterior, a industrialização passasse a ser um dos protagonistas do crescimento da capital e da sua região metropolitana

O processo de mudanças empreendido pelo conjunto de ações dos anos 1980 em diante aprofundariam a metropolização, imprimindo-Ihe feições mais nítidas com intensificação, modernização e diversificação de serviços, transformações na dinâmica de divisão do trabalho do espaço metropolitano renovando os eixos de ocupação da economia (RUFINO, 2009, p. 15).

A Tabela 6, com o tamanho populacional dos municípios da RMF e os do Ceará como um todo, subsidia a compreensão temporal deste processo. Os municípios vão sendo inseridos na Tabela à medida que foram incorporados à RMF, embora alguns deles já fossem emancipados desde os anos 1970 (como é o caso de Cascavel, Pacajus e São Gonçalo do Amarante).

\footnotetext{
3 A RMF, criada em 1973 juntamente com as demais RM's, originalmente contava com cinco municípios (Fortaleza, Caucaia, Maranguape, Aquiraz e Pacatuba). Foi ampliada em 1986, com o desmembramento de Maracanaú do município de Maranguape (ocorrido em 1983), em 1991, com a inclusão de Eusébio e Guaiúba, em 1999, com a entrada de Itaitinga, Chorozinho, Pacajus e São Gonçalo do Amarante e, em 2009, incluindo Pindoretama e Cascavel. (LCF 14/73; LCF 52/86; LE 11.845-91; LCE 18/99 E LCE 78/09).
} 
A primeira constatação importante é a manutenção do crescimento da RMF superior ao estadual em todos os períodos considerados. Isto ocorre principalmente nas duas primeiras décadas. Tal comportamento e o gradual aumento do número de municípios metropolitanos culmina com um quadro de forte concentração populacional na RMF, alcançando em 2010 a parcela de $42,8 \%$ da população estadual. Com o passar do tempo, progressivamente vai se observando uma redução do crescimento populacional do núcleo metropolitano, substituído por aqueles municípios que vão se sobressaindo nas atividades econômicas com destaque para Caucaia, Maranguape e Pacatuba num primeiro momento, e depois pelos demais municípios que se integram à RMF como Horizonte, Eusébio e Maranguape.

No conjunto, toda a RMF teve incremento nos períodos apontados. A redução em Maranguape entre 1980-1991, e em Pacatuba no período seguinte decorre dos respectivos desmembramentos dos municípios de Maracanaú e Itaitinga. Os dois novos municípios continuam fazendo parte da RMF.

Tabela 6 - Ceará e RMF: População Total 1970-2010.

\begin{tabular}{|c|c|c|c|c|c|c|c|c|c|c|}
\hline & \multicolumn{2}{|c|}{1970} & \multicolumn{2}{|c|}{1980} & \multicolumn{2}{|c|}{1991} & \multicolumn{2}{|c|}{2000} & \multicolumn{2}{|c|}{2010} \\
\hline & Pop. & $\%$ & Pop. & $\%$ & Pop. & $\%$ & Pop. & $\%$ & Pop. & $\%$ \\
\hline$\overline{R M F}$ & 1.036 .779 & 23,79 & 1.580 .069 & 29,88 & 2.149 .866 & 33,77 & 2.950 .899 & 39,71 & 3.615 .767 & $\overline{42,78}$ \\
\hline Aquiraz & 32.507 & 0,75 & 45.112 & 0,85 & 46.305 & 0,73 & 60.469 & 0,81 & 72.628 & 0,86 \\
\hline Cascavel & & & & & & & & & 66.142 & 0,78 \\
\hline Caucaia & 54.754 & 1,26 & 94.106 & 1,78 & 165.099 & 2,59 & 250.479 & 3,37 & 325.441 & 3,85 \\
\hline Chorozinho & & & & & & & 18.707 & 0,25 & 18.915 & 0,22 \\
\hline Eusébio & & & & & 20.410 & 0,32 & 31.500 & 0,42 & 46.033 & 0,54 \\
\hline Fortaleza & 857.980 & 19,69 & 1.307 .608 & 24,73 & 1.768 .637 & 27,78 & 2.141 .402 & 28,82 & 2.452 .185 & 29,01 \\
\hline Guaiúba & & & & & 17.562 & 0,28 & 19.884 & 0,27 & 24.091 & 0,29 \\
\hline Horizonte & & & & & & & & & 55.187 & 0,65 \\
\hline Itaitinga & & & & & & & 29.217 & 0,39 & 35.817 & 0,42 \\
\hline Maracanaú & & & & & & & 179.732 & 2,42 & 209.057 & 2,47 \\
\hline Maranguape & 59.622 & 1,37 & 91.137 & 1,72 & 71.705 & 1,13 & 88.135 & 1,19 & 113.561 & 1,34 \\
\hline Paca & & & & & & & 44.070 & 0,59 & 61.838 & 0,73 \\
\hline Pacatuba & 31.916 & 0,73 & 42.106 & 0,80 & 60.148 & 0,94 & 51.696 & 0,70 & 72.299 & 0,86 \\
\hline Pindoretama & & & & & & & & & 18.683 & 0,22 \\
\hline $\begin{array}{l}\text { São } \\
\text { Gonçalo do } \\
\text { Amarante }\end{array}$ & & & & & & & 35.608 & 0,48 & 43.890 & 0,52 \\
\hline $\begin{array}{l}\text { CEARÁ- } \\
\text { RMF }\end{array}$ & 3.320 .661 & 76,21 & 3.708 .360 & 70,12 & 4.216 .781 & 66,23 & 4.479.762 & 60,29 & 4.836 .614 & 57,22 \\
\hline
\end{tabular}


Fonte: Censos Demográficos (1970; 1980; 1991; 2000; 2010)

$\mathrm{Na}$ dinâmica econômica, é possível traçar algumas notas fundadas na realidade dada pela espacialidade contida nos indicadores da estrutura produtiva. No caso da Indústria de Transformação, ramo em que mais se direcionaram ações governamentais com medidas e programas específicos objetivando a interiorização, há clara configuração de uma "desconcentração concentrada".

Observou-se que dos investimentos industriais subvencionados, Fortaleza deixa de ser o principal destino. Porém, estes permanecem em grande peso relativo nos municípios da sua RM. O espraiamento em direção a outros municípios metropolitanos passa a priorizar por ordem de importância os municípios de Maracanaú, Caucaia, Eusébio, Cascavel, Aquiraz, Itaitinga e São Gonçalo do Amarante. Ademais, vale destacar que outros municípios não metropolitanos recebem investimentos industriais em ramos mais tradicionais, ficando os setores mais dinâmicos na RMF como Equipamentos de Informática e Eletrônicos, Químicos, Equipamentos de Transporte, Farmoquímicos, dentre outros. Houve ainda a expansão do Polo Têxtil de Maracanaú, com a implantação de 22 novos empreendimentos que geraram 26,5 mil novos empregos (CEDE, 2010).

A elevada participação da RMF é confirmada também através da análise que tem como corte o PIB Industrial, que dá a dinâmica do PIB como um todo (Tabela 7). A evolução de desconcentração metropolitana é clara com redução da participação de Fortaleza sendo absorvida por outros municípios também não metropolitanos, tendo em vista que sua queda é bem maior que a expansão da RMF como um todo.

Tabela 7 - Ceará e RMF: Participação no PIB Industrial (\%) 1970-2010.

\begin{tabular}{lrrrrr}
\hline & $\mathbf{1 9 7 0}$ & $\mathbf{1 9 8 5}$ & $\mathbf{1 9 9 1}$ & $\mathbf{2 0 0 0}$ & $\mathbf{2 0 1 0}$ \\
\hline RMF & 69,4 & 70,7 & 77,6 & 71,5 & 71,9 \\
Aquiraz & 0,3 & 0,9 & 1,6 & 1,4 & 1,6 \\
Cascavel & 0,4 & 0,4 & 1,2 & 1,3 & 0,8 \\
Caucaia & 1,6 & 2,4 & 2,5 & 3,2 & 4,7 \\
Chorozinho & & & & 0,1 & 0,1 \\
Eusébio & & & & 3,1 & 3,6 \\
Fortaleza & 62,5 & 60,7 & 61,5 & 40,6 & 42,0 \\
Guaiúba & & & & 0,1 & 0,1 \\
Horizonte & & & & 2,5 & 2,7 \\
Itaitinga & & & & 0,2 & 0,3 \\
Maracanaú & & & 7,5 & 13,9 & 11,2 \\
Maranguape & 3,0 & 4,1 & 1,4 & 1,2 & 1,6
\end{tabular}




\begin{tabular}{lrrrrr} 
Pacajus & 1,0 & 1,4 & 1,1 & 2,6 & 1,1 \\
Pacatuba & 0,7 & 0,5 & 0,5 & 1,1 & 1,3 \\
Pindoretama & & & & 0,1 & 0,1 \\
São Gonçalo do Amarante & & 0,1 & 0,1 & 0,3 & 0,8 \\
CEARÁ-RMF & 30,6 & 29,3 & 22,4 & 28,5 & 28,1 \\
CEARÁ & $\mathbf{1 0 0 , 0}$ & $\mathbf{1 0 0 , 0}$ & $\mathbf{1 0 0 , 0}$ & $\mathbf{1 0 0 , 0}$ & $\mathbf{1 0 0 , 0}$ \\
\hline
\end{tabular}

Fonte: IBGE (2012)

No setor Terciário a desconcentração com a redução de participação metropolitana também é detectada, conforme foi verificado na Tabela 4. Muito contribuiu a expansão do ramo de Comércio com a difusão dos padrões de consumo urbanos pelo interior, manifestados na grande expansão do Comércio Varejista.

Este e outros movimentos da relativa redução do papel da metrópole precisam ser melhor adjetivados contemporizando-os a outros fenômenos. A conversão da metrópole em capital de atividades como o turismo, com aprimoramento em ramos ligados à atividade é outro indicativo desta transformação demonstrado na expansão do número de estabelecimentos do setor e imprimindoIhe um aspecto de "metrópole híbrida" dividida entre as atividades da indústria e do turismo (PAIVA, 2011).

Também se processa mesma dinâmica em outros ramos especializados e mais sofisticados, como o de Serviços Auxiliares das Atividades Econômicas, que incluem atividades de consultoria e processos decisórios de comando sobre a produção e demais serviços. Nestes, a metrópole dita o maior crescimento (Ver Tabela 4).

O papel firmado pela metrópole cearense é portanto um dos instrumentos em grande envergadura de apropriação espacial. Concentrando atividades de comando, desconcentrando atividades produtivas para as quais as margens à escala são mais amplas em espaços espraiados a partir do seu eixo de influência, a metropolização não se desvincula dos ajustes, tendo um papel estratégico na captura dos fluxos sobre o espaço cearense e seus vínculos com arenas diversificadas. As amarras são inteiradas por outras estruturas urbanas que espacializam a lógica dos ajustes.

O papel das cidades médias.

Em decorrência dos papéis funcionais desempenhados no exercício de suas influências, o padrão de cidade média aqui considerado é o de centros cujas hierarquias apontam para a atuação de funções articuladoras em nível regional, por meio de relações de intermediação entre um relativo número de cidades pequenas e 
os centros maiores (SPÓSITO, 2007, p. 234). Extrapola-se assim as limitações dadas pela utilização única no critério do tamanho populacional.

Utilizou-se como referência as distinções hierárquicas dadas pelo IBGE através do estudo sobre Regiões de Influência de Cidades (REGIC 2008). De acordo com este estudo, o sistema urbano do estado está hierarquizado nos seguintes níveis: após a Metrópole Regional Fortaleza, estão destacadas as Capitais Regionais C de Sobral e Crato-Juazeiro do Norte-Barbalha, seguidas pelos Centros Sub-regionais A de Crateús, Iguatu e Quixadá, pelo Centro Sub-regional B de Itapipoca e pelos 17 Centros de Zona divididos nas categorias A e B. Os demais núcleos urbanos são classificados como Centro Locais sendo o nível de classificação mais elementar.

Mesmo considerando que existe determinado exercício desta função por parte dos Centros de Zona, admitiu-se o desempenho primordial pelas cidades com níveis hierárquicos superiores a este. Desta forma, além das Capitais Regionais C de Sobral e Crato-Juazeiro do Norte-Barbalha, serão considerados os Centros Subregionais A de Crateús, Iguatu e Quixadá, o Centro Sub-regional B de Itapipoca ${ }^{4}$.

Além das funções de influências apontadas pelo REGIC 2008, a relevância destes centros no panorama estadual é verificada por alguns indicadores exibidos na Tabela 8. Entre 1991 e 2010, o conjunto formado pelos seis centros expandiu sua participação estadual tanto em população quanto em PIB: de 11,3\% para 11,6\% na população e de $9,1 \%$ para $10,2 \%$ do PIB. As variações podem parecer sutis. No entanto, quando se considera que, excluindo-se os municípios de Itapipoca e Sobral, se trata de municípios mais afastados das externalidades metropolitanas, elas ganham relevância.

Tabela 8 - Cidades Médias do Ceará: População, Taxa de Urbanização (\%) e Participação no PIB Estadual (\%) 1991-2010.

\begin{tabular}{|c|c|c|c|c|c|c|c|c|c|c|c|c|}
\hline & \multicolumn{4}{|c|}{1991} & \multicolumn{4}{|c|}{2000} & \multicolumn{4}{|c|}{2010} \\
\hline & Pop. & $\begin{array}{l}\% \\
\text { CE }\end{array}$ & Urb. & $\begin{array}{c}\% \\
\text { do } \\
\text { PIB } \\
\text { CE }\end{array}$ & Pop. & $\begin{array}{l}\% \\
\mathrm{CE}\end{array}$ & Urb. & $\begin{array}{c}\% \\
\text { do } \\
\text { PIB } \\
\text { CE }\end{array}$ & Pop. & $\begin{array}{l}\% \\
\text { CE }\end{array}$ & Urb. & $\begin{array}{c}\% \\
\text { do } \\
\text { PIB } \\
\text { CE }\end{array}$ \\
\hline $\begin{array}{l}\text { Crato-J. } \\
\text { do Norte- } \\
\text { Barbalha }\end{array}$ & 302.515 & 4,8 & 85,8 & 3,3 & 36.3810 & 4,9 & 87,1 & 3,8 & 426.690 & 5,0 & 88,8 & 4,2 \\
\hline Crateús & 66.652 & 1,0 & 59,9 & 0,7 & 70.898 & 1,0 & 67,1 & 0,5 & 72.812 & 0,9 & 72,3 & 0,5 \\
\hline Iguatu & 75.649 & 1,2 & 70,2 & 1,2 & 85.615 & 1,2 & 72,8 & 1,0 & 96.495 & 1,1 & 77,3 & 1,0 \\
\hline
\end{tabular}

${ }^{4}$ Embora sejam três cidades, o aglomerado Crato-Juazeiro do Norte-Barbalha tem tratamento em comum devido à dinâmica conjunta na polarização e influência conjunta exercida pelos três centros conforme abaliza o REGIC 2008. 


\begin{tabular}{lrrrr|rrrr|rrrr} 
Itapipoca & 77.263 & 1,2 & 44,9 & 0,8 & 94.369 & 1,3 & 51,4 & 0,8 & 116.065 & 1,4 & 57,6 & 0,8 \\
Quixadá & 72.224 & 1,1 & 54,6 & 1,1 & 69.654 & 0,9 & 67,3 & 0,6 & 80.604 & 1,0 & 71,3 & 0,7 \\
Sobral & 127.489 & 2,0 & 81,5 & 2,1 & 155.276 & 2,1 & 86,6 & 3,4 & 188.233 & 2,2 & 88,4 & 3,0 \\
TOTAL & 721.792 & 11,3 & & 9,1 & 839.622 & 11,3 & & 10,2 & 980.899 & 11,6 & & 10,2 \\
\hline Onte: Censos & Demográficos (IBGE, 1991; $2000 ; 2010) ;$ PIB's Municipais (IBGE, 1985-2010).
\end{tabular}

No caso das duas Capitais Regionais C, sendo centros maiores e de hierarquia mais elevada, é natural que sejam detentores das mais altas participações e também melhores desempenhos entre os dois anos observados. A disposição geográfica dos dois núcleos permite que exerçam polarização alcançando com suas influências a grande parte do território estadual, através da oferta de comércio e serviços diversificados em ambas ${ }^{5}$. Juntamente com as atividades econômicas já analisadas destaca-se o papel dos serviços de educação e saúde. São dois centros com sedes de universidades públicas, institutos tecnológicos, de pesquisa e saúde, com os maiores hospitais do interior cearense.

A cidade média de Sobral, localizada na Mesorregião Noroeste, tem ainda sobre a sua área de influência importantes cidades considerados pelo REGIC 2008 como Centro de Zonas A e B, como Acaraú, Itapajé, Cruz, Camocim, Guaraciaba do Norte, Ipu e São Benedito, formando um subsistema urbano bem articulado. As conexões formadas descreve fortes nexos entre cidade e campo numa Mesorregião com um bom desempenho agrícola em nível estadual.

O mesmo processo não ocorre com Crato-Juazeiro do Norte e Barbalha que dispõe de apenas um Centro de Zona B classificado na sua mesorregião, que é a cidade de Brejo Santo. No entanto, é importante lembrar que o aglomerado CratoJuazeiro do Norte-Barbalha, exerce grande concentração econômica e populacional sobre a Mesorregião Sul Cearense: este conjunto de cidades participa com $48 \%$ e $81 \%$ da população e do PIB mesorregional (IPECE, 2010). Motivado por esta concentração bem como pelo fato de se constituir num espaço urbano contínuo, em junho de 2009, foi criada a Região Metropolitana do Cariri (RM Cariri), compreendida por esta conurbação e mais seis municípios limítrofes (Jardim, Missão Velha, Caririaçu, Farias Brito, Nova Olinda e Santana do Cariri) ${ }^{6}$.

\footnotetext{
5 Tendo como referência as linhas de transportes coletivo disponíveis na base de dados do REGIC 2008, Sobral e Crato-Juazeiro do Norte-Barbalha têm ligações respectivamente com outros 42 e 43 municípios de hierarquias inferiores abrangendo a grande parcela do território estadual e também algumas áreas dos estados vizinhos.

6 Efetivada pela LCE 78/09. Contudo, a institucionalização da RMC está inserida no amplo debate sobre processos e fatos metropolitanos. A sua criação foi muito mais resultado de medidas governamentais agrupada no conjunto de ações objetivando descongestionamento/concentração na RMF.
} 
Complementando o grupo de centros intermediários aqui considerados, os Centros Sub-regionais de Crateús, Iguatu e Quixadá tem perfil de desenvolvimento e inserção regionais parecidos. O contexto de suas mesorregiões, Sertões Cearenses e Centro Sul Cearense, abrangem espaços de predomínio de agricultura de subsistência e pecuária, com atividades tradicionais arrefecidas. Compõem o espaço em que até os anos 1980 dedicava-se quase que com exclusividade ao cultivo do algodão e à pecuária extensiva.

O processo de modernização agrícola não contemplou de forma nítida estes espaços e a influência exercida por Crateús, Iguatu e Quixadá abarca uma área com inúmeras pequenas cidades que se enquadram nas denominadas "economias sem produção"7. Limitada dinâmica foi empreendida com a implantação de empresas extra regionais do setor de calçados $^{8}$, como parte das estratégias de interiorização da indústria. A área de influência destes centros abrange a zona estratégica de instalação dos empreendimentos deste setor, oferecendo profundas isenções fiscais e mão de obra abundante, deslocadas da agricultura declinante. Seus efeitos maiores são sobre as atividades de comércio que tem crescimento nas duas mesorregiões (Ver Tabela 4).

Dos centros caracterizados como intermédios, o de dinâmica menos expressiva é Crateús, que entretanto também teve empreendimentos implantados no ramo calçadista, como extensão de plantas previamente atuantes em Quixadá e Canindé (CEDE, 2010). Na agricultura, a modernização não avançou nitidamente na sua incorporação aos circuitos da agricultura moderna se se considera que as principais atividades estimuladas estão voltadas para a pecuária tradicional da ovinocaprinocultura. Constitui-se em parcela não inserida na lógica de produção regulada pelo mercado, apontada por Elias (2007, p. 451), referindo-se ao processo de desintegração competitiva do semiárido com outros espaços cearenses eleitos para a transformação.

O Centro Sub-regional de Itapipoca, com uma localização favorável ao seu crescimento, tem influência sobre algumas cidades situadas nas suas proximidades desempenhando relação de conexão entre estas e a capital do Estado. Os fluxos são mais rápidos devido ao fato de estar nas extremidades da RMF o que favorece

\footnotetext{
7 São casos predominantes no semiárido nordestino onde as economias giram em torno dos recursos advindos de transferências governamentais como previdência social, transferências intergovernamentais, emprego público e transferências de renda familiar constituídas pelo Programa Bolsa Família. (ARAÚJO e LIMA, 2009, p. 48).

${ }^{8}$ A Dakota S. A. instalouse em Iguatu e Quixadá, empregando em conjunto entre 1.000 a 1.200 trabalhadores. (CEDE, 2010).
} 
também ao seu crescimento populacional que, dentre os centros em questão obteve o maior crescimento nesta variável, crescendo 2,2\% a.a. entre 1991 e 2010.

A funcionalidade dada por estes núcleos urbanos ao avanço do desenvolvimento capitalista no Ceará é requisital para as acomodações da divisão espacial do trabalho. Considerados como intermediários nas articulações da rede urbana em questão, as intermediações que efetuam transferem para os territórios sob sua influência os vetores dos ajustes espaciais. Como derivações estão o aumento gradativo de suas participações nas atividades econômicas e na dinâmica populacional.

A sua relação com a atividade industrial é controvertida, diferentemente de casos em que os centros intermediários assumiram papel mais ativo na espacialização das atividades econômicas. No caso de redes urbanas mais equilibradas - que no Brasil tem como exemplo o complexo que se formou no interior de São Paulo (CANO, 2002, p. 70), a consolidação das condições do desenvolvimento capitalista provoca cada vez mais o deslocamento da indústria para os centros médios movidos por reestruturações que evitam a elevação dos custos e deseconomias de aglomeração (PENALVA, 2010, p 107). No percurso, centros urbanos dotados de infraestrutura e aptos na oferta de economias de escala são os espaços determinados para a expansão da atividade.

Aqui, a relocação para estes centros médios provocadas pela reestruturação se dá em outros padrões, articulada com a restruturação ampla que impõe maior competitividade. Num macro ambiente de ausência de política industrial coordenada em nível nacional, os locais de destinos de investimentos se convertem, mormente, em meras plataformas receptoras.

O papel desempenhado de intermediação entre o grande centro metropolitano e a hinterlândia rural e pequenas cidades é ativo. De um lado, sua influência permite arregimentar mão de obra a baixo custo das áreas que lhe são tributárias e, de outro, através da ligação com a metrópole conecta-se ao mercado externo para onde direciona a produção dos seus bens. O mesmo processo é verificado com as atividades agrícolas, comprovado pela ascensão de algumas cidades a níveis hierárquicos mais elevados em decorrência da modernização das atividades agrícolas como foi o caso do complexo de centros urbanos formados por Limoeiro do Norte, Morada Nova e Russas, na Mesorregião Jaguaribe.

A inserção das pequenas cidades. 
No decurso dos ajustes tratados, um papel importante é atribuído às pequenas cidades da rede, que se justifica por ser a unidade urbana que mais atributos cumpre nas relações entre cidade e campo, sendo qualificada como a fronteira entre os processos rurais e urbanos (DAMIANI, 2006, p. 135).

Nos estudos clássicos sobre as hierarquias urbanas, o grau de influência dos centros refere-se às complexidades dos bens e serviços que justificam os fluxos. Sendo as cidades pequenas a expressão de mais baixo nível no exercício das influências, esta complexidade se revelaria portanto mais baixa, associada às funções de consumo imediato e reprodução das condições de vida, caracterizandoas como cidades locais (SANTOS, 2008, p. 56). As pequenas aglomerações urbanas não se desvinculam assim do papel de cidade econômica estratégica em decorrência do seu tamanho.

Todavia, Damiani (2006, p. 137) expõe que a apropriação dos avanços da modernidade pelas pequenas cidades ocorre de maneira residual por se localizarem na ponta inferior da articulação de um modo de produção que é eminentemente urbano. Em realidades periféricas, o aprofundamento deste pressuposto é válido quando funcionalmente convivem estruturas de produção com diferentes temporalidades como no caso das formas pré-capitalistas que, no caso da agricultura do Nordeste, são ainda tão presentes em relações não assalariadas como as parcerias na produção pelo uso da terra.

Em contrapartida, dado o caráter restrito proporcionado pela eleição de espaços com a implantação de modernos polos de agricultura irrigada, os pequenos centros urbanos não incluídos nestas áreas continuam a exercer funções de fronteira entre processos urbanos em mutação e processos rurais reprodutores de velhas estruturas.

A sua magnitude é observada quando se leva em conta os mesmos indicadores já apresentados para as cidades intermediárias revelando inclusive o papel que estas cumprem ao exercer influência sobre as pequenas cidades. Ao se versar sobre uma conexão intermediária, está se tratando de uma articulação entre grandes cidades signo do capitalismo moderno e internacionalizado e um universo imenso de população, recursos e margens ociosas de expansão a serem mobilizados, constituídos pelos pequenos centros. Na Tabela 9 observa-se que apesar da redução na participação da população total do estado, o contingente populacional residente nas pequenas cidades do Ceará em 2010 era superior a um terço $(39,2 \%)$ e, ainda que com taxas menores, continuou tendo um crescimento 
populacional positivo de 1,3\%a.a. e 1\%a.a nos períodos de 1991-2000 e de 20002010.

Tabela 9 - Cidades Pequenas do Ceará: População, Taxa de Urbanização (\%) e Participação no PIB Estadual (\%) 1991-2010.

\begin{tabular}{l|ccccc}
\hline & População & \% CE & Urb. & $\begin{array}{c}\text { \% do PIB } \\
\text { CE }\end{array}$ & $\begin{array}{c}\text { \% do PIB Agrícola } \\
\text { Estadual }\end{array}$ \\
\hline $\mathbf{1 9 9 1}$ & 2.673 .158 & 42,0 & 39,6 & 22,9 & 64,54 \\
$\mathbf{2 0 0 0}$ & 3.000 .988 & 40,4 & 48,7 & 21,9 & 70,47 \\
$\mathbf{2 0 1 0}$ & 3.310 .127 & 39,2 & 54,6 & 22,8 & 68,42
\end{tabular}

Fonte: Censos Demográficos (IBGE, 1991; 2000; 2010); PIB's Municipais (IBGE, 1985-2010).

O aumento no grau de urbanização destas cidades, de 39,6\% em 1991 para 54,6\% em 2010 pode revelar algumas faces dos movimentos demográficos como um possível padrão step-wise de deslocamento da população começando o movimento pelo êxodo rural para estes pequenos centros ${ }^{9}$. Entretanto, essa constatação carece de melhores aprofundamentos, com uma dedicada análise dos indicadores populacionais por um período de tempo mais longo, estabelecendo sequencialmente comparações com centros de níveis hierárquicos maiores.

A expansão da participação destes municípios no PIB Agrícola estadual é decorrente de dois fatores. O primeiro é por abranger aqueles pequenos centros que agregam os espaços de implantação da agricultura moderna como Icapuí, Quixeré, Morada Nova (na Mesorregião Jaguaribe), Ubajara e Ibiapina (na Mesorregião Noroeste Cearense), Mauriti (na Mesorregião Sul Cearense). Juntos estes centros abrangeram em 1985, 2000, 2010, respectivamente $6,7 \%, 11,1 \%$ e $14,1 \%$ do total do PIB Agrícola dos pequenos centros aqui considerados (IBGE, 2010). O segundo fator decorre do menor peso da agropecuária em outros grupos de municípios (as cidades intermediárias e a RMF), onde os serviços e a indústria detêm participações mais amplas.

Levando em consideração estes fatores, se excluído do grupo as cidades da agricultura modernizada, é plausível a conclusão de que a dinâmica econômica prevalecente no grupo de cidades pequenas do Ceará é limitada, reservando-lhes um perfil econômico vulnerável e dependente. São espaços se observam a reprodução daquelas "economias sem produção" a que se fez referência em outra

\footnotetext{
${ }^{9}$ Segundo Corrêa (2011, p. 31) é o padrão de migração com realização de itinerário em etapas por centros urbanos com hierarquias maiores.
} 
parte do trabalho. As economias giram em torno dos recursos advindos de transferências governamentais como a previdência social, as transferências intergovernamentais, o emprego público e as transferências de renda a familiar constituídas pelo Programa Bolsa Família. (ARAÚJO e LIMA, 2009, p. 48).

\section{Considerações Finais}

Conforme apontado na Introdução, buscou-se com o presente trabalho estudar as alterações nas composições urbano-regionais cearenses tendo como referência as transformações que acompanharam o processo de reestruturação econômica apontando para nítidos ajustes espaciais.

Acompanhando as transformações macro conjunturais cujo ápice foi a reversão no paradigma de regulação com a emergência do padrão neoliberal de intervenção, o Ceará vivenciou a partir de meados dos anos 1980 um conjunto de alterações figuradas na política e na economia com fortes efeitos territoriais. Ancoraram as transformações um conjunto de medidas pautados na renovação administrativa, na modernização produtiva puxada pela agricultura irrigada, atração de empreendimentos industriais via subsídios, melhorias infraestruturais.

Em resposta à problematização colocada, observou-se de fato a consolidação dos três perfis de arranjos estruturais urbanos articulando os ajustes espaciais na proposição harveyana de atendimento às convocações das transformações da acumulação capitalista.

Além da renovação do processo de metropolização, com espraiamento populacional e produtivo, forte macrocefalia exercida por Fortaleza e sua RM, emergem um grupo de núcleos formado por alguns centros médios focos da atração de empreendimentos na maioria das vezes no setor calçadista. São polos intermediários entre a metrópole e as áreas mais rurais, conectando hinterlândias adjacentes em prol da drenagem de recursos que forjam os mecanismos de ajustes.

Estes três arranjos - metrópoles, cidades intermédias e cidades pequenas conduzem as reorganizações espaciais das mudanças expressas na rede urbana e confirmam a hipótese de ajustes da rede cearense como implicação da dinâmica de mudanças do desenvolvimento capitalista. Suas aproximações aos requerimentos macro conjunturais são marcantes: a metropolização intensificada, conectando diretamente aos circuitos globais, a emergência de pequeno número de centros intermediários coadjuvando estas conexões e um extenso complexo de pequenas 
cidades vinculadas ao rural predominantemente tradicional e imutável, à exceção daquelas áreas selecionadas pela agricultura moderna.

\section{REFERÊNCIAS}

AMORA. Z. B. Indústria e espaço no Ceará. In: BOZARCCHIELLO, J. CAVALCANTE, T. e DANTAS, E. Ceará: um novo olhar geográfico. 2ª ${ }^{2}$ Ed. Fortaleza: Edições Demócrito Rocha, 2007.

BERNAL, C., A metrópole emergente: a ação do capital imobiliário na estruturação urbana de Fortaleza. Fortaleza: Editora UFC; BNB, 2004.

BRANDÃO, C. B. Território e desenvolvimento: as múltiplas escalas entre o global e o local. Campinas: Editora da UNICAMP, 2007.

CANO, W. Ensaios sobre a crise urbana no Brasil. Campinas: EDUNICAMP, 2011.

Desconcentração produtiva regional no Brasil (1970-2005). 3ª. Ed. São Paulo: Editora da UNESP, 2008.

Ensaios sobre a formação econômica regional do Brasil. Campinas: Editora da UNICAMP, 2002.

CEDE. Conselho Econômico de Desenvolvimento Estadual do Ceará. Protocolo de Empresas Incentivadas Instaladas. 2010

CORRÊA, R. L. Trajetórias geográficas. 6ª . Ed. Rio de Janeiro: Bertrand do Brasil, 2011.

Estudos sobre rede urbana. Rio de Janeiro: Bertrand Brasil, 2006.

. O espaço urbano. 3ª Ed. Rio de Janeiro, 1995. (Série Princípios).

A rede urbana. 2ª . Ed. São Paulo: Editora Ática, 1994. (Série Princípios).

COSTA, M. C. L. da e AMORA, Z. B. Transformações nas cidades médias do Ceará (Brasil). Anales del XII Encuentro de Geógrafos de America Latina. Montevidéu, Uruguai, 3 y 7 de abril de 2009. Disponível http://observatoriogeograficoamericalatina.org.mx/egal12/Geografiasocioeconomica/Geografi aurbana/246.pdf. Acesso em 20/jun/2012.

DAMIANI, A. L. Cidades médias e pequenas no processo de globalização. Apontamentos bibliográficos. In: LEMOS, A. I. G., ARROYO, M. e SILVEIRA, M. L. América Latina: cidade, campo e turismo. São Paulo: CLACSO, 2006. p. 135-147.

DANTAS, E. W. C e SILVA, J. B. A formação histórica da metrópole e principais tendências do desenvolvimento. In: PEQUENO, L. R. (org.) Como anda Fortaleza. Rio de Janeiro: Observatório das Metrópoles; Letra Capital, 2009. p. 1-36.

DIÁRIO DO NORDESTE. Região Metropolitana tem eficácia questionada. Caderno de Política. 28/ago/2012.

ELIAS, D. Desigualdade e pobreza no espaço agrário cearense. Mercator - Revista de Geografia da UFC. Fortaleza. Volume 2. Número 3. p. 61-69. jan/jun 2003. 
FURTADO, C. Formação econômica do Brasil. 34ํㅗ Ed. São Paulo: Companhia das Letras, 2007

GOUVEIA, R. G. A questão metropolitana no Brasil. Rio de Janeiro: Editora FGV, 2005.

HARVEY, D. Os limites do capital. São Paulo: Boitempo Editorial, 2013.

2010.

. The enigma of capital: the crises of capitalismo. London, UK: Profile Books,

Annablume, 2005.

A produção capitalista do espaço. Trad. Carlos Szlak. 2ª . Ed. São Paulo:

IBGE. Região de Influência de Cidades - REGIC. Brasília, DF: FIBGE, 2008

Censos Demográficos. Anos Selecionados..

LENCIONE, S. Reconhecendo metrópoles: território e sociedade. In: SILVA, C. A. da, FREIRE, D. G. e OLIVEIRA, F. J. G. (Orgs.) Metrópole: governo, sociedade e território. Rio de Janeiro: DP\&A: FAPERJ, 2006.

MACEDO, F. C. de, LIMA JÚNIOR, F. O. de e MORAIS, J. M. L. de. Dinâmica econômica e rede urbana cearense no início do século XXI. Revista REDES, Santa

PARENTE, J. e ARRUDA, J. M A Era Jereissati: modernidade e mito. Fortaleza: Edições Demócrito Rocha, 2002.

PEQUENO, L. R. B. (Org. Como anda Fortaleza? Rio de Janeiro: Letra Capital; Observatório das Metrópoles, 2009.

ROCHEFORT, M. Redes e sistemas: Ensinando sobre o Urbano e a Região. Trad. Antônio de Pádua Danesi. São Paulo: Editora Hucitec, 1998.

RUFINO, M. B. C. Desenvolvimento industrial e organização espacial: algumas considerações sobre a Região Metropolitana de Fortaleza. Anais do XIII Encontro Nacional da ANPUR. Florianópolis, SC. 25 a 29 de maio de 2009.

SANTOS, M. A urbanização brasileira. 5a․ Ed. São Paulo: EDUSP, 2008.

. Espaço e método. São Paulo: Editora Nobel, 1985.

SECEX - MDIC. Dados de Exportações municipais. 2013

SPOSITO, M. E. B. A produção do espaço urbano: escalas, diferenças e desigualdades socioespaciais. In: CARLOS, A. F. A., SOUZA, M. L. e SPÓSITO, M. E. B. (Orgs.). A produção do espaço urbano: agentes e processos, escalas e desafios. São Paulo: Editora Contexto, 2012.

\section{NOTAS DE AUTOR}

\section{CONTRIBUIÇÃO DE AUTORIA}

Francisco do O' de Lima Júnior - Concepção. Coleta de dados, Análise de dados, Elaboração do manuscrito, revisão e aprovação da versão final do trabalho. 
Fundação Cearense de Apoio ao Desenvolvimento Científico e Tecnológico (FUNCAP) com concessão de Bolsa de Doutorado.

\section{CONSENTIMENTO DE USO DE IMAGEM}

Não se aplica

APROVAÇÃO DE COMITÊ DE ÉTICA EM PESQUISA

Não se aplica.

\section{CONFLITO DE INTERESSES}

Não e aplica

\section{LICENÇA DE USO}

Este artigo está licenciado sob a Licença Creative Commons CC-BY. Com essa licença você pode compartilhar, adaptar, criar para qualquer fim, desde que atribua a autoria da obra.

\section{HISTÓRICO}

Recebido em: 18-10-2017

Aprovado em: 10-07-2018 